\title{
A survey on the intercultural communicative competence of ELT undergraduate students
}

\author{
Aylin Sevimel-Sahin ${ }^{\mathrm{a}}$ * (1) \\ a Anadolu University, Faculty of Education, ELT Department, Eskisehir 26470, Turkey
}

\begin{tabular}{l|l|l} 
Received 9 August 2019 & Received in revised form 7 March 2020 & Accepted 26 March 2020
\end{tabular}

\begin{abstract}
APA Citation:
Sevimel-Sahin, A. (2020). A survey on the intercultural communicative competence of ELT undergraduate students. Eurasian Journal of Applied Linguistics, 6(2), 141-153.
\end{abstract}

Doi: $10.32601 /$ ejal.775793

\begin{abstract}
Intercultural communicative competence (ICC) is the ability to communicate effectively and appropriately with other cultures to negotiate meaning. A high level of ICC is required for a successful communication across numerous cultures. Since English has recently been accepted as the main intercultural communication language among different cultures, teaching/learning English has gained popularity. As long as learners master English and understand its cultural contexts, they are better at intercultural communication, which results from the ICC level. Hence, there is a relationship between the development of ICC and the development in the target language. Based on this idea, the current study aims to investigate the ICC levels of undergraduate English language teaching students to find out the effect of language competence on intercultural communicative competence, and also whether there is a change throughout the four-year teacher training program. A total of 238 first-year and fourth-year undergraduate ELT students were surveyed. The collected data revealed a high level of ICC regardless of study year. It also yielded a significant difference between first-year students' ICC and fourth-year students' ICC, which means mastering in English positively affects the ICC level. In accordance with the results, some implications were shared.
\end{abstract}

(C) 2020 EJAL \& the Authors. Published by Eurasian Journal of Applied Linguistics (EJAL). This is an open-access article distributed under the terms and conditions of the Creative Commons Attribution license (CC BY-NC-ND) (http://creativecommons.org/licenses/by-nc-nd/4.0/).

Keywords: communication; culture; English language teaching; intercultural communicative competence; undergraduate student

\section{Introduction}

In recent years, there has been an increasing globalization due to a number of factors such as business, education, technology, tourism, and so on around the world. As a result of this globalization, international relations have increased; and thus, it makes intercultural communication, namely cross-cultural communication, a requisite. As we all know, we need languages in order to communicate. Among numerous foreign languages, the English language is accepted as a lingua franca because it has been spoken by millions of non-native speakers as a medium of

\footnotetext{
* Corresponding author. Tel.: +90-222-335-05-80

E-mail address: aylinsevimel@anadolu.edu.tr http://dx.doi.org/10.32601/ejal.775793
} 
instruction in order to provide mutual understanding all over the world (Kramsch, 2001; Ryan, 2012). In other words, English as a lingua franca (ELF) has substituted for many other foreign languages either at a national or regional level owing to its widespread use for intercultural communication (Han, 2013; Kramsch, 2001). In addition to ELF, the term English as an international language (EIL) has been used to stress the international and global status of the language for all the countries other than only English-speaking west countries (Ryan, 2012; Sifakis, 2019). Therefore, the use of ELF/EIL emphasizes the fact that understanding the cultural contexts as well as their practices of communication are needed for successful international communication across various cultures (Han, 2013). That is to say, not only the knowledge of a language itself, but also the knowledge of its culture is essential in such communication performances. Thus, it can be said that learning a foreign language necessitates an engagement with its culture because learning to communicate with others in the target language means communicating with their culture (Liddicoat, 2005).

As far as the significance of ELF within intercultural communication is considered, it can be argued that learning/teaching of the English language has gained much importance than ever to communicate across various cultures. In this respect, the research showed that it is fundamental to prepare learners 'to engage and collaborate in a global society by discovering appropriate ways to interact with people from other cultures' (Moeller \& Nugent, 2014, p. 2). However, to carry out a smooth and effective intercultural communication via a shared language, i.e., English, it is necessary to have sufficient knowledge of the cultural context of the target language and its lingua-cultural conventions. It is because language and culture are acknowledged to be intrinsically connected, and inseparable for communication (Hua, 2014; Liddicoat, 2005). The other reason behind the scene is that culture maintains the context of a language; that is, on the one hand, cultural components provide principal motivation for language use, and on the other hand, they lead to gaining new perspectives and broadening the world views and perceptions of language learners (Corbett, 2003; Zhou \& Griffiths, 2011). As a result of this, language learners can easily engage in global communication.

This inextricable relationship of language and culture, and also the status of ELF for intercultural communication have obviously influenced the objectives of foreign language education since it has been recognized that not only acquiring the knowledge and skills of that language but also using that language appropriately in social and cultural contexts are highly important (Byram, Gribkova, \& Starkey, 2002; Cakir, 2006). Therefore, the major goal of English language education has shifted from improving only linguistic competence of language learners to enhancing also their communicative competence integrated with its cultural characteristics, namely, intercultural communicative competence (ICC) (Genc \& Bada, 2005; Hoa, 2011). As a consequence, the present situation of English language education indicates that to improve ICC of language learners has become one of the main goals to prepare 
learners for the global communication while making them competent language learners (Alptekin, 2002; Byram, 2000; Hismanoglu, 2011; Sercu, 2006).

\section{Review of Literature}

\subsection{The conceptual framework}

In English language education, culture is considered to be the fifth skill accompanied by the other skills such as speaking, listening, writing, and reading in addition to the knowledge of its grammar, vocabulary, and pronunciation. Since there is interplay of language and culture, which is inseparable for communication, culture provides the background knowledge to master the communicative functions of the target language. That is, it is required to make sense of cultural contexts of the language to communicate effectively in intercultural situations (Frank, 2013; Lai, 2014). To fulfill the aim of producing interculturally competent language learners, it is needed to improve their ICC because 'effective communication across cultures requires communicators to have excellent ICC' (Zheng, 2014, p. 73).

ICC originally emerged as being complementary to Hymes' notion of communicative competence (Atay, Kurt, Camlibel, Ersin, \& Kaslioglu, 2009; Byram, Holmes, \& Savvides, 2013; Huang, 2014). It basically refers to the ability to interact effectively and appropriately as well as to behave flexibly when encountered with other cultures in order to maintain a shared understanding (Byram, 2000; Byram, Gribkova \& Starkey, 2002; Meyer, 1991). From the point of foreign language learning, ICC indicates the 'activities related to behavior and speech patterns such as appropriate choices for conversation topics, ..., and non-verbal communication' (Hismanoglu, 2011, p. 805). Thus, ICC should have certain characteristics in order to deal with intercultural experiences. Sercu (2005) pointed out those characteristics, which lead to the construction of the content of ICC, as:

The willingness to engage with the foreign culture, self-awareness and the ability to look upon oneself from the outside, the ability to see the world through the others' eyes, the ability to cope with uncertainty, the ability to act as a cultural mediator, the ability to evaluate others' points of view, the ability to consciously use culture learning skills and to read the cultural context, and the understanding that individuals cannot be reduced to their collective identities (p. 2).

In view of such characteristics, a number of researchers have discussed the content of ICC in the literature (e.g. Byram, 2000; Byram et al., 2002; Baker, 2012; Deardorff, 2006; Fantini, 2012; Hismanoglu, 2011; Huang, 2014; Lai, 2014). Among these researchers, Byram (2000) has been acknowledged to be the leading figure, for the others have supported his model of ICC. According to his model, ICC has mainly three components: knowledge, skills, and attitudes (see Figure 1). The component of knowledge includes different communicative practices in diverse socio-cultural settings, cultural awareness, culture-specific information and sociolinguistic information; the component of skills consists of the ability to use that knowledge in an appropriate and flexible way by listening, observing, interpreting, analyzing, 
evaluating and relating; and the component of attitudes comprises the ability to respect others, to tolerate ambiguity and uncertainty, to acknowledge other identities, to empathize, and to be tolerant of others' values and beliefs (Byram, 2000; Baker, 2012; Deardorff, 2006).

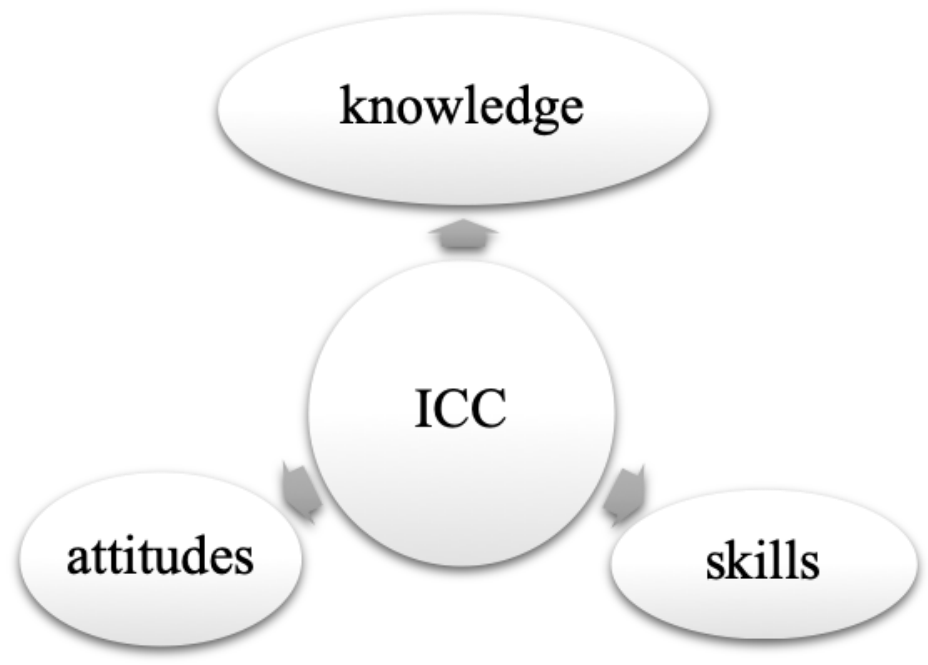

Figure 1. The components of intercultural communicative competence

As far as the model and the components are considered, ICC is believed to have a developmental characteristic; that is, it is not permanent, but it is 'a lifelong learning' (Zheng, 2014, p. 76). Therefore, ICC can be developed by improving the cultural knowledge, attitudes and behaviors related to the language, all of which are crucial for successful intercultural communication (Alptekin, 2002; Baker, 2012; Ozuorcun, 2014). This can also be achieved by development in the language since the development in the language brings about the improvement in ICC (Fantini, 2012). Similarly, as Young and Sachdev (2011) put forward that 'the link between the ability to function effectively in a foreign language and the clusters of skills, knowledge and attitudes which can be acquired or changed' can contribute to the enhancement of ICC (p. 86). Hence, it can be concluded that there is a relationship between development in a foreign/second language and development of ICC (Fantini, 2012).

\subsection{Review of relevant research studies}

The research into ICC has over fifty years of history with the pioneer researcher Edward T. Hall, but the studies on ICC have recently increased and become important due to the growth of communication across multicultural communities (Arasaratnam \& Doerfel, 2005). In the literature, the initial ICC studies mostly investigated how individuals across diverse cultures comprehend each other (Kramsch, 2001). However, differently, the current studies within the scope of ICC have been found to focus on culture teaching rather than ICC teaching, especially regarding English major, most of the time (Liu, 2009). 
In the field of English Language Teaching (ELT) within the context of pre-service education, more recent studies in ICC have generally dealt with the relationship between ICC and a number of variables such as gender, overseas experiences, language proficiency, studying abroad, motivation, the impact of explicit teaching on ICC and so on. For instance, Hismanoglu (2011) found that having high levels of linguistic proficiency, overseas experience, and explicit teaching; that is, formal instruction specifically on ICC led to higher levels of ICC of pre-service ELT students. In a similar vein, Saricoban and $\mathrm{Oz}$ (2014) concluded that studying abroad was effective in the development of ICC, though the variables of gender and grade point average (GPA) did not make any contribution to the higher levels of ICC of pre-service ELT students. Moreover, Mirzaei and Forouzandeh (2013) established the association that the motivation to learn English was influential in ICC development of Iranian English major students. Lastly, Sarigoz (2014) explored the impact of ELT teacher education program only on one of the components of ICC; namely, intercultural awareness in the knowledge category of pre-service students, and he found that learning a foreign language contributed to the students' intercultural awareness as well as their personal development, and future professional performances. Therefore, the studies showed that especially being abroad and high levels of proficiency in the target language contributed to the development of ICC. In addition, the common finding within the field of ICC research should be highlighted: ICC is a central factor for successful intercultural communication in general. It has also a key role in learning a foreign/second language in particular (Mirzaei \& Forouzandeh, 2013) while it has a developmental nature (Zheng, 2014) as well as there is a reciprocal effect between language learning and ICC development (Fantini, 2012).

All in all, considering the study results and the arguments discussed within the scope of ICC, it can be expected that in English teacher education programs, undergraduate ELT students have much more exposure to the language because they intensively study the English language to teach it in their future classes, and are also considerably engaged in different aspects of the language. Hence, they have more likely much more knowledge of the language itself as well as its background, namely, its culture. As the arguments of Fantini (2012), Young and Sachdev (2011), and Zheng (2014) are considered, it can be assumed that while training programs influence the language development, ICC can also develop in the same line when undergraduate students are graduated. Therefore, it might be notable to investigate ICC levels of undergraduate ELT students in order to find out whether the teacher training program leads to a change in the development of ICC levels from the first year of the program to the last year. Besides, unlike the other studies mentioned earlier (e.g. Hismanoglu, 2011; Saricoban \& Oz, 2014; Mirzaei \& Forouzandeh, 2013; Sarigoz, 2014), the current study focuses on the effect of the ELT program on the development of undergraduate ELT students' ICC and its components considering the training years. To this end, the purpose of the present study is to explore the levels of ICC of ELT students, and also to examine the difference between the first-year and the 
fourth-year students' ICC levels to evaluate whether there is a change throughout the training years. For these aims, the following research questions guide the research:

1. What are the ICC levels of the first-year and the fourth-year undergraduate ELT students?

2. Is there a difference between the first-year and the fourth-year undergraduate ELT students' ICC levels?

\section{Method}

\subsection{Participants}

A total of 238 undergraduate students who were enrolled in the ELT department at a state university in Turkey participated in the present study. The convenience sampling method was preferred because the students were available due to their convenient accessibility when the study was carried out. In the sample, there were 116 first-year, and 122 fourth-year students who participated in the research on a voluntary basis. Besides, there were more female undergraduate ELT students $(n=162)$ than male students $(n=76)$. All of them spoke Turkish as their mother tongue and learned English as their foreign language. Their age was between 17 and 30.

\subsection{Instrument}

The current study is based on a survey design. Therefore, as an instrument, the Intercultural Communicative Competence Questionnaire (ICCQ) by Mirzaei and Forouzandeh (2013) was used in order to investigate the ICC of the undergraduate ELT students. In the ICCQ, there are 22 items in total, and the questionnaire has three components which are knowledge, skills, and attitudes, and based on a 5-point Likert scale. 12 of the items are organized under the 'knowledge' component which is about cultural awareness and information; 5 of them belong to the 'skills' component related to communicative abilities such as listening, interpreting, and relating; and the rest 5 items belong to the 'attitudes' component that assess the characteristics of the sample regarding cultural issues such as respecting, being open to, and tolerating diversities. Moreover, 7 items in the questionnaire are reverse coded as carried out by Saricoban and $\mathrm{Oz}(2014)$.

In addition to the ICCQ, an information note about the research, a consent form, and a background information questionnaire were given to the participants in order to inform them, to obtain their consents, and to collect their demographic information for the study.

\subsection{Data collection}

The present research was started with ethical considerations before the questionnaire was administered. First, the permissions of the lecturers/instructors were taken since their class times were considered to collect data. Then, the 
questionnaire in English was distributed to all of the first- and fourth-year undergraduate ELT students in their weekly courses. It took approximately 10 minutes to fill the questionnaire. The incomplete questionnaires and the students who did not volunteer were eliminated. In the end, 238 questionnaires were obtained for the data analysis.

\subsection{Data analysis}

All of the collected data were analyzed by using the following listed statistical methods via IBM SPSS Statistics 20 program.

For the first research question, the mean scores were computed in order to determine the levels of overall ICC as well as its components. The obtained mean scores would indicate that the higher the mean is, the higher the level of ICC is. Also, the number of participants and their percentages per category in the criteria suggested by Saricoban and $\mathrm{Oz}$ (2014) were calculated. These criteria, then, were used to show the distribution of the categorical data regarding the ICC levels in the sample (high, moderate, and low level of the ICC of undergraduate ELT students):

$$
\begin{array}{ll}
\text { High level } & : 3.50<\mathrm{M}<5.00 \\
\text { Moderate level } & : 2.50<\mathrm{M}<3.49 \\
\text { Low level } & : 1.00<\mathrm{M}<2.49
\end{array}
$$

For the second research question, an independent samples t-test was conducted to examine whether there was a difference between the first-year and the fourth-year undergraduate ELT students' ICC levels.

Lastly, Cronbach's alpha coefficient was calculated for the reliability of the questionnaire.

\section{Results and Discussion}

In the current study, the ICC levels, and the difference between the first- and fourth-year undergraduate ELT students regarding their ICC were investigated by applying the ICCQ instrument. The ICCQ instrument was found at the acceptable level of reliability in this study ( $\alpha=.78)$.

When the data analysis related to the ICC levels of the participants was performed, it was found that the whole sample, no matter what their study year was, had a high level of ICC in terms of the overall mean score $(M=3.88)$ (see Table 1$)$. Both the firstyear students' ICC level $(M=3.82)$ and the fourth-year students' ICC level $(M=3.93)$ were high. The levels of each component of ICC; knowledge $(M=3.86)$, skills $(M=3.89)$, and attitude $(M=3.90)$ were also high; especially, the category of attitude in total.

When the two groups are compared, it is seen that the ICC level of the fourth-year students $(M=3.93)$ is slightly higher than the first-year students' ICC level $(M=3.82)$. As far as the categories of knowledge, skills, and attitudes of ICC are taken into 
account, the mean scores for each category for the first-year students are somewhat lower than the fourth-year students (see Table 1).

Table 1 . The mean distribution of the ICC level within the sample $(N=238)$

\begin{tabular}{lcccc}
\hline & ICC: Knowledge & ICC: Skills & ICC: Attitude & \multicolumn{2}{c}{ ICC: Total } \\
\cline { 2 - 5 } & $\mathrm{M}$ & $\mathrm{M}$ & $\mathrm{M}$ & $\mathrm{M}$ \\
\cline { 2 - 5 } First-year $(\mathrm{n}=116)$ & 3.81 & 3.80 & 3.85 & 3.82 \\
Fourth-year $(\mathrm{n}=122)$ & 3.91 & 3.98 & 3.96 & 3.93 \\
Total & 3.86 & 3.89 & 3.90 & 3.88 \\
\hline
\end{tabular}

As far as the distribution of the levels of ICC among the sample is considered, it was found that there was only one participant with a low level of ICC (see Table 2). Nearly all the participants are within the high levels of ICC $(n=202)$. Furthermore, there were more participants with high levels of ICC in the fourth year $(n=111)$ than in the first year $(n=91)$.

Table 2. The categorical distribution of ICC level of the sample

\begin{tabular}{lcccccc}
\hline & \multicolumn{9}{c}{ ICCQ.total } \\
\cline { 2 - 7 } & \multicolumn{2}{c}{ high level } & \multicolumn{2}{c}{ moderate level } & \multicolumn{2}{c}{ low level } \\
\cline { 2 - 7 } & $\mathrm{n}$ & $\%$ & $\mathrm{n}$ & $\%$ & $\mathrm{n}$ & $\%$ \\
\cline { 2 - 7 } First-year (n=116) & 91 & 78.4 & 24 & 20.7 & 1 & 0.9 \\
Fourth-year (n=122) & 111 & 91.0 & 11 & 9.0 & 0 & 0 \\
Total (N=238) & 202 & 84.9 & 35 & 14.7 & 1 & 0.4 \\
\hline
\end{tabular}

In order to find out if there is a difference between the ICC levels of the first- and fourth-year undergraduate ELT students in the study, an independent samples t-test was conducted. The result of the test revealed a statistically significant difference between the ICC levels of the first-year students and the fourth-year students $(p=.021)$, which means that the study year has a significant effect on the levels of ICC of the participants. As the components of ICC are considered, a statistically significant difference in terms of ICC skills was found between the first-and the fourth-year students $(p=.014)$. However, there was not a significant difference between the first- and the fourth-year students' ICC knowledge ( $p=.067)$ nor their ICC attitudes $(p=.103)$ (see Table 3$)$. Thus, it can be concluded that the study year significantly affected the level of ICC, and it revealed a significant difference between two groups of participants' ICC level, specifically in the category of ICC skills.

Table 3. The difference between two groups of participants about their ICC

\begin{tabular}{lccc}
\hline First-year \& Fourth-year & $\mathrm{t}$ & $\mathrm{df}$ & $\mathrm{p}^{*}$ \\
\hline ICC: Knowledge & -1.837 & 236 & .067 \\
ICC: Skills & -2.472 & 236 & .014 \\
ICC: Attitude & -1.683 & 236 & .103 \\
ICC: Total & -2.234 & 236 & .021 \\
\hline
\end{tabular}

${ }^{*} \mathrm{p}<0.05$ 
When all of the findings are evaluated, it is clear that ELT undergraduate students reported that their ICC level was high. This result indicates that they perceived themselves to be highly aware of the culture related information, and to have the abilities of engaging with foreign cultures appropriately and flexibly, which was also underlined by Sercu (2005) as the important characteristics of ICC. This conclusion may also be attributed to the definitions of ICC (e.g. Byram, 2000; Meyer, 1991) in that ELT undergraduate students regarded themselves as having the ability to interact effectively, flexibly and appropriately when confronted with intercultural communication situations while having the awareness of the aforementioned characteristics. In addition, it is most likely that the ELT program contributed to the development of undergraduate students' ICC though there was no course on the explicit teaching of ICC as studied by Hismanoglu (2011). Hence, the necessary knowledge, skills and attitudes were assumed to be transferred to the ELT undergraduates while making them be more culturally aware as well as more effective communicators throughout the training years.

When the significant difference regarding the study year on the overall ICC level and the result that the ICC level of the fourth-year students was higher than the ICC level of the first-year students are considered, it can be concluded that the overall ICC of undergraduate ELT students improved from the first year to the last year of their study in the teacher training program. This finding indicates that ICC is not stable, and it can change and improve through linguistic development during the training period as supported by Fantini (2012), Young and Sachdev (2011), and Zheng (2014). However, when the non-significant differences are taken into consideration, it can be noted that there was not any development with regard to certain components of ICC. For instance, there was not much change related to ICC knowledge (e.g., different communication practices, cultural awareness, culture-specific information, sociolinguistic information) and ICC attitudes (e.g. respecting others and valuing cultural diversity, being open, tolerance for ambiguity and uncertainty) of the undergraduate ELT students. This finding demonstrates that the ELT program may not be as successful as promoting those components of ICC. Yet, there is a significant difference with respect to ICC skills between the first-year and the fourth-year students. It shows that ELT undergraduate students perceived themselves to be improved in terms of the necessary skills (e.g. listening, observing, interpreting) to cope with cultural issues in communicative performances more easily and effectively from the first year of study to the last year of study. Therefore, it can be recognized that the ELT program led to the development of ICC of the ELT undergraduate students along their training years as the findings of the current study yielded.

\section{Conclusions}

The present study was designed to investigate whether the ELT program affects the development of ICC of undergraduate students throughout their training years. The overall findings of the ICCQ produced that nearly the whole sample had high levels of ICC, but the last-year students had slightly higher level of ICC compared to 
the first-year students. Furthermore, there was a statistically significant difference regarding the effect of study year on the ICC development, which means that the ELT program had a role in the improvement of the participants' ICC levels despite the lack of explicit instruction in ICC. On the other hand, though the overall ICC, and the ICC skills enhanced throughout the study years, there was not much improvement in terms of cultural knowledge and attitudes. Hence, there is a paramount task for teachers to support the development of all the ICC dimensions. It can be suggested that culture-specific knowledge and information may be explicitly highlighted or studied in the ELT courses to promote the ICC knowledge dimension. It is recommended because although language learners are exposed to the topics of literature, science, society and culture implicitly by means of learning a foreign language (English) and via practicing speaking, writing, listening and reading, explicit instruction in cultural knowledge can be helpful for the enhancement of ICC. To achieve this purpose, different cultural samples might be studied more explicitly to influence the attitudes of the students towards cultural diversity. The strategies suggested by Han (2013) can also be utilized and underlined by the teachers in the program to foster the ICC: 'to know yourself, to increase cultural awareness, to enhance motivation, and to obtain cultural knowledge' (pp. 9-10). Likewise, Reid (2015) shared techniques of improving ICC in English language classes such as comparison method, cultural assimilation, cultural capsule, cultural island, reformulation, prediction, and so on. They can be used in language skills courses while providing the background in teacher training programs. Therefore, to create intercultural awareness through such tasks or activities while learning/teaching a foreign language is indispensable for ICC development. It is because awareness is the link among the subcategories of ICC. As Sifakis (2019) argued, it can be concluded that teacher training programs are responsible for creating awareness in terms of ICC. That is, pre-service teachers should gain ICC through adopting ELF awareness and perspective so as to assist their future students to develop sufficient ICC when they practice English (Toprakoglu \& Dilman, 2017).

As for further studies, it can be recommended that since the sample studied in the present research shared the same mother tongue, and learned only one foreign language (English), another sample learning more than one foreign language or bilinguals can be studied in order to investigate their ICC. It can also be suggested that the effect of other variables apart from the program effect, proficiency, gender, and the like may be analyzed. For example, the effect of the Internet in which ELF has a widespread use; that is, being globally connected via the Internet by means of the mutual language (English) may be explored in order to find out if it is effective in the improvement of the cultural components of communicative competence.

\section{The Conflict of Interest Statement}

In line with the statement of Committee on Publication Ethics (COPE), I hereby declare that we had no conflicting interests regarding any parties of this study. 


\section{References}

Alptekin, C. (2002). Towards intercultural communicative competence in ELT. ELT Journal, 56(1), 57-64.

Arasaratnam, L. A., \& Doerfel, M. L. (2005). Intercultural communication competence: Identifying key components from multicultural perspectives. International Journal of Intercultural Relations, 29(2), 137-163. https://doi.org/10.1016/j.ijintrel.2004.04.001

Atay, D., Kurt, G., Camlibel, Z., Ersin, P., \& Kaslioglu, O. (2009). The role of intercultural competence in foreign language teaching. Inonu University Journal of the Faculty of Education, 10(3), 123-135.

Baker, W. (2012). From cultural awareness to intercultural awareness: Culture in ELT. ELT Journal, 66(1), 62-70. https://doi.org/10.1093/elt/ccr017

Byram, M. (Ed.). (2000). Routledge encyclopedia of language teaching and learning (1st ed.). NY: Taylor \& Francis Routledge.

Byram, M., Gribkova, B., \& Starkey, H. (2002). Developing the intercultural dimension in language teaching: A practical introduction for teachers. Strasbourg: Council of Europe.

Byram, M., Holmes, P., \& Savvides, N. (2013). Intercultural communicative competence in foreign language education: Questions of theory, practice and research. The Language Learning Journal, 41(3), 251-253. https://doi.org/10.1080/09571736.2013.836343

Corbett, J. (2003). An intercultural approach to English language teaching. UK: Multilingual Matters Ltd.

Cakir, I. (2006). Developing cultural awareness in foreign language teaching. Turkish Online Journal of Distance Education, 7(3), 154-161.

Deardorff, D. K. (2006). Identification and assessment of intercultural competence as a student outcome of internalization. Journal of Studies in International Education, 10(3), 241-266. https://doi.org/10.1177/1028315306287002

Fantini, A. (2012). Language: An essential component of intercultural communicative competence. In J. Jackson (Ed.), The Routledge handbook of language and intercultural communication (pp. 263-278). UK: Taylor \& Francis Group, Routledge Publishing.

Frank, J. (2013). Raising cultural awareness in the English language classroom. English Teaching Forum, 51(4), 2-11.

Genc, B., \& Bada, E. (2005). Culture in language learning and teaching. The Reading Matrix, $5(1), 73-84$.

Han, Y. (2013). Research on fostering intercultural communication competence of foreign language learners. Cross-Cultural Communication, 9(1), 5-12.

http://dx.doi.org/10.3968/j.ccc.1923670020130901.2890

Hismanoglu, M. (2011). An investigation of ELT students' intercultural communicative competence in relation to linguistic proficiency, overseas experiences and formal instruction. International Journal of Intercultural Relations, 35, 805-817. https://doi.org/10.1016/j.ijintrel.2011.09.001

Hoa, N. T. M. (2011). Developing EFL learners' intercultural communicative competence: A gap to be filled? Journal of English as an International Language: From Defining EIL Competence to Designing EIL Learning, 86-99.

Hua, Z. (2014). Exploring intercultural communication: Language in action. UK: Taylor \& Francis Group, Routledge Publishing.

Huang, Y. (2014). Constructing intercultural communicative competence framework for English learners. Cross-Cultural Communication, 10(1), 97-101.

http://dx.doi.org/10.3968/j.ccc.1923670020141001.3970 
Kramsch, C. (2001). Intercultural communication. In R. Carter \& D. Nunan (Eds.), The Cambridge guide to teaching English to speakers of other languages (pp. 201-206). Cambridge, UK: CUP.

Lai, H. Y. T. (2014). Learning English as an international language: EFL learners' perceptions of cultural knowledge acquisition in the English classroom. Asian Social Science, 10(1), 111. http://dx.doi.org/10.5539/ass.v10n1p1

Liu, J. (2009). Students' construal of intercultural communication competence and intercultural communication teaching. Intercultural Communication Studies, 18(2), 88-102.

Liddicoat, A. J. (2005). Teaching languages for intercultural communication. In D. Cunningham \& A. Hatoss (Eds.), An international perspective on language policies, practices and proficiencies (pp. 201-214). Belgrave: Editura Fundației Academice Axis \& Fédération Internationale des Professeurs de Langues Vivantes.

Meyer, M. (1991). Developing transcultural competence: Case studies of advanced foreign language learners. In D. Buttjes \& M. Byram (Eds.), Mediating languages and cultures (pp. 136-158). Clevedon: Multilingual Matters.

Mirzaei, A., \& Forouzandeh, F. (2013). Relationship between intercultural communicative competence and L2-learning motivation of Iranian EFL learners. Journal of Intercultural Communication Research, 42(3), 300-318. https://doi.org/10.1080/17475759.2013.816867

Moeller A. J., \& Nugent K. (2014). Building intercultural competence in the language classroom. In S. Dhonau (Ed.), 2014 Report of the central states conference on the teaching of foreign languages (pp. 1-18). Richmond, VA: Robert M. Terry.

Ozuorcun, F. (2014). Teaching culture as a fifth skill. The Journal of International Social Research, 7(29), 680-685.

Reid, E. (2015). Techniques developing intercultural communicative competence in English language lessons. Procedia-Social and Behavioral Sciences, 186, 939-943. https://doi.org/10.1016/j.sbspro.2015.04.011

Ryan, P. (2012). The English as a foreign or international language classroom. In J. Jackson (Ed.), The Routledge handbook of language and intercultural communication (pp. 422-433). UK: Taylor \& Francis Group, Routledge Publishing.

Saricoban, A., \& Oz, H. (2014). Research into pre-service English teachers' intercultural communicative competence (ICC) in Turkish context. Anthropologist, 18(2), 523-531.

Sarigoz, I. H. (2014). The effects of foreign language learning on intercultural awareness of non-native EFL teacher trainees. International Online Journal of Education and Teaching (IOJET), 1(5), 332-346.

Sercu, L. (2005). Teaching foreign languages in an intercultural world. In L. Sercu (Ed.), Foreign language teachers and intercultural competence: An international investigation (pp. 1-18). UK: Multilingual Matters Ltd.

Sercu, L. (2006). The foreign language and intercultural competence: The acquisition of a new professional identity. Intercultural Education, 17(1), 55-72. https://doi.org/10.1080/14675980500502321

Sifakis, N. C. (2019). ELF awareness in English language teaching: Principles and processes. Applied Linguistics, 40(2), 288-306. doi:10.1093/appling/amx034

Toprakoglu, M., \& Dilman, H. (2017). ELF awareness in English language education. International Journal of Language Academy, 5(5), 39-58. http://dx.doi.org/10.18033/ijla.3618

Young, T. J., \& Sachdev, I. (2011). Intercultural communicative competence: Exploring English language teachers' beliefs and practices. Language Awareness, 20(2), 81-98. https://doi.org/10.1080/09658416.2010.540328 
Zheng, J. (2014). Assessing intercultural communicative competence in college English teaching. International Journal of English Language Teaching, 1(2), 73-77. https://doi.org/10.5430/ijelt.v1n2p73

Zhou, C., \& Griffiths, C. (2011). Intercultural communicative competence. English Language and Literature Studies, 1(2), 113-122. http://dx.doi.org/10.5539/ells.v1n2p113

\section{Copyrights}

Copyright for this article is retained by the author(s), with first publication rights granted to the Journal.

This is an open-access article distributed under the terms and conditions of the Creative Commons Attribution license (CC BY-NC-ND) (http://creativecommons.org/licenses/by-nc-nd/4.0/). 